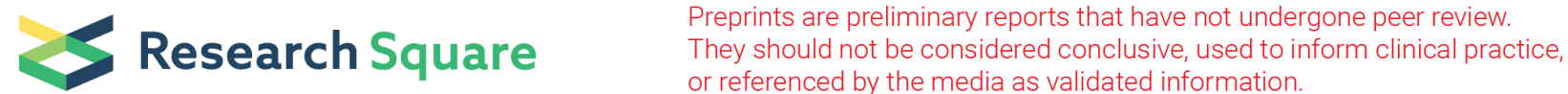

\section{Significance of placental swab in diagnosing vertical transmission in SARS-CoV-2 positive mothers.}

Isabelle Sweeney ( $\nabla$ sweeneyi@tcd.ie )

University of Limerick https://orcid.org/0000-0002-7694-2593

Niazy Al Assaf

University Maternity Hospital Limerick

Rizwan Khan

University Maternity Hospital Limerick

\section{Systematic Review}

Keywords: pregnant COVID-19 positive mothers, fetal vertical transmission, placental swabs

Posted Date: August 26th, 2020

DOI: https://doi.org/10.21203/rs.3.rs-62590/v2

License: (c) (i) This work is licensed under a Creative Commons Attribution 4.0 International License.

Read Full License 


\section{Abstract}

\section{Aims}

Currently, there is limited date on the effects of COVID-19 on pregnancy and neonatal outcome. This literature review aims to investigate the possibility of fetal vertical transmission in COVID-19 positive pregnant mothers by diagnosing through placental swabs.

\section{Methods}

The search terms 'pregnant COVID-19 positive mothers', 'fetal vertical transmission' and 'placental swabs' were used. 11 papers were selected for this review.

\section{Results}

This literature review comprises 45 COVID-19 positive pregnant women whose placentas and neonates were also analysed by RT-PCR for the presence of SARS-CoV-2. 43 neonates were successfully delivered primarily via caesarean section out of 45 expectant mothers (96\%). 2 mothers did not deliver due to severe preeclampsia and a miscarriage both occurring in the second trimester. 3 neonates tested positive for SARS-CoV-2 (7\%). We report no neonatal mortality after birth and no maternal mortality. 8 female's placentas tested positive for SARS-CoV-2 out of a total of 45 tested (18\%). Of these 8,2 cases of SARSCoV-2 were identified in the maternal, neonatal and placental tissue.

\section{Conclusion}

After reviewing multiple studies and investigating the nature of placental physiology in SARS-CoV-2 positive mothers we conclude that there is no concrete evidence of vertical transmission occurring between mother and infant. However, there are inconsistencies across the different papers used for this review and further research investigating the effects of COVID-19 on pregnant women by using RT-PCR to test the mother, placenta, vaginal fluid, breast milk and infant for SARS-CoV-2 at various stages of transmission is urgently needed.

\section{Introduction}

On March 11 2020, the World Health Organisation declared that the pneumonia outbreak of coronavirus disease 2019 (COVID-19), caused by the severe acute respiratory syndrome coronavirus 2 (SARS-CoV-2) is a pandemic [1]. Due to its highly transmissible nature, as of July 12020 , there was a total of 10,446,353 confirmed cases of COVID-19, including 511,037 deaths across the five continents [2]. With COVID-19's sustained spread across the globe, pregnant women are unfortunately not indiscriminate from contracting the virus. This may be attributed to the changes to the cardiorespiratory and immune system during pregnancy thereby increasing a woman's susceptibility to severe infection and hypoxic compromise [3]. 
Lopes de Sousa et al published a systematic review in June 2020 and concluded that there is no concrete evidence for vertical transmission of COVID-19 but acknowledged that significant knowledge gaps exist and they cannot rule out this possibility [4]. The presence of COVID-19 has been assessed in neonates born to COVID-19 positive mothers by examining the placenta, and carrying out nucleic acid testing on breast milk and vaginal mucus [5-7].

Two epidemics in the past two decades, namely severe acute respiratory syndrome (SARS-CoV) in 2002 and Middle East respiratory syndrome coronavirus (MERS-CoV) in 2014 promote more serious complications than COVID-19 during pregnancy with approximately one third of infected pregnant women dying from the illness [3]. However, similarly to COVID-19, there have been no documented cases of vertical transmission seen in SARS or MERS to date [8].

Today, the effects of COVID-19 on pregnancy and neonatal outcome are being studied in real-time by researchers across the globe. This paper aims to review the current literature regarding the possibility of fetal vertical transmission in COVID-19 positive pregnant mothers by diagnosing through placental swabs.

\section{Methods}

Articles were searched using the following databases: Pubmed, ScienceDirect, Medline, Embase, Web of Science.

All studies in the review were selected using these databases, none were hand-selected. Studies relating to pregnant COVID-19 positive mothers and fetal vertical transmission and placental swabs were selected.

We followed the guidelines according to PRISMA, MOOSE, Cochrane Handbook of Systematic Reviews of Interventions.

Search terms used were: Pregnant COVID-19 positive mothers + fetal vertical transmission + placental swabs

Inclusion criteria: Studies performed on above terminologies along with overlapping of terminologies from September 2019 to present.

Exclusion criteria: Studies performed prior to September 2019.

There are no conflicts of interest.

\section{Results}

A review of studies focusing on pregnant COVID-19 positive mothers and placental swabs in the context of fetal vertical transmission has been performed. The eleven studies we reviewed are summarised in 
table one.

\section{Maternal Outcome}

This literature review comprises 45 COVID-19 positive pregnant women whose placentas and neonates were also analysed by RT-PCR for the presence of SARS-CoV-2. We report no maternal mortality [9-19]. One woman opted for termination of pregnancy due to symptomatic SARS-CoV-2 complicated by severe preeclampsia in the second trimester [15]. Another woman with symptomatic SARS-CoV-2 presented in the second trimester with a miscarriage [17].

\section{Neonatal Outcome}

43 neonates were successfully delivered primarily via caesarean section out of 45 expectant mothers (96\%). 3 neonates tested positive for SARS-CoV-2 (7\%). We report no neonatal mortality after birth. Yu et al reported one neonate who was delivered via caesarean section testing positive at 36 hours after birth. This neonate had mild shortness of breath and x-ray findings of mild pulmonary infection. At 28 days after birth, the neonate was healthy and had no respiratory symptoms. SARS-CoV-2 was not identified in the mother's placental tissue though infection was confirmed in the mother's throat swab [11].

Patanè et al reported two neonates testing positive who both remained asymptomatic. One was vaginally delivered and tested positive immediately after birth, 24 hours later and 7 days later. After delivery, skin-toskin contact was not permitted but breastfeeding with a mask was allowed. The other positive neonate was delivered by emergency caesarean section due to a non-reassuring fetal status and tested positive only on day 7 after birth. There was no contact between the mother and neonate during this period as the newborn was immediately separated and transferred to the neonatal intensive care unit [14].

\section{Laboratory Investigations}

Serial RT-PCR identified SARS-CoV-2 in 8 female's placentas out of a total of 45 tested (18\%). Of these 8 , Patanè et al's study is the first and only study we have identified which reports 2 cases of SARS-CoV-2 in the maternal, neonatal and placental tissue. Both of these mothers displayed signs and symptoms of SARS-CoV-2 [14]. Penfield et al reported 3 positive placentas in women with severe to critical SARS-CoV-2 [13]. Interestingly, SARS-CoV-2 was also identified in the placentas of both mothers who did not deliver their neonate due to severe preeclampsia and a miscarriage $[15,17]$. We report one case of a positive placenta in a woman with asymptomatic SARS-CoV-2 who presented to the hospital due to a breech presentation [16].

Table 1. Summary of studies relating to vertical fetal transmission in COVID-19 positive pregnant mothers by diagnosing through placental swabs [9-19]. 


\begin{tabular}{|c|c|c|c|c|}
\hline Paper & $\begin{array}{l}\text { Date of } \\
\text { publication }\end{array}$ & $\begin{array}{l}\text { Number } \\
\text { of } \\
\text { placentas } \\
\text { analysed } \\
\text { (45) }\end{array}$ & Place & Results \\
\hline \multirow[t]{6}{*}{$\begin{array}{l}\text { Wang et } \\
\text { al } 9\end{array}$} & \multirow{6}{*}{$\begin{array}{l}28 \\
\text { February } \\
2020\end{array}$} & \multirow[t]{6}{*}{1} & \multirow{6}{*}{$\begin{array}{l}\text { Suzhou, } \\
\text { China }\end{array}$} & $\begin{array}{l}\text { Case: } 28 \text { year old COVID-19 positive mother } \\
\text { at } 30 \text { weeks gestation. }\end{array}$ \\
\hline & & & & Delivery: Emergency caesarean section. \\
\hline & & & & $\begin{array}{l}\text { Variables tested: Neonate's nasopharyngeal } \\
\text { swab, amniotic fluid, placenta, umbilical cord } \\
\text { blood, and gastric juice. }\end{array}$ \\
\hline & & & & $\begin{array}{l}\text { Results: All negative for SARS-CoV-2 via RT- } \\
\text { PCR. }\end{array}$ \\
\hline & & & & Timing of placenta analysis: During delivery. \\
\hline & & & & Vertical transmission: Inconclusive evidence. \\
\hline \multirow[t]{6}{*}{$\begin{array}{l}\text { Fan et al } \\
10\end{array}$} & \multirow[t]{6}{*}{$\begin{array}{l}17 \text { March } \\
2020\end{array}$} & \multirow[t]{6}{*}{2} & \multirow[t]{6}{*}{$\begin{array}{l}\text { Wuhan, } \\
\text { China }\end{array}$} & $\begin{array}{l}\text { Case: } 34 \text { and } 29 \text { year old COVID- } 19 \text { positive } \\
\text { mother at } 37 \text { and } 36 \text { weeks gestation } \\
\text { respectively. }\end{array}$ \\
\hline & & & & Delivery: Caesarean section. \\
\hline & & & & $\begin{array}{l}\text { Variables tested: Neonate's nasopharyngeal } \\
\text { swab, maternal serum, placenta, umbilical } \\
\text { cord blood, amniotic fluid, vaginal swabs and } \\
\text { mother's breast milk. }\end{array}$ \\
\hline & & & & $\begin{array}{l}\text { Results: All negative for SARS-CoV-2 via RT- } \\
\text { PCR. }\end{array}$ \\
\hline & & & & $\begin{array}{l}\text { Timing of placenta analysis: Above named } \\
\text { specimens collected 'at or during delivery'. }\end{array}$ \\
\hline & & & & Vertical transmission: Inconclusive evidence. \\
\hline \multirow[t]{6}{*}{$\begin{array}{l}\text { Yu et al } \\
11\end{array}$} & \multirow[t]{6}{*}{$\begin{array}{l}24 \text { March } \\
2020\end{array}$} & \multirow[t]{6}{*}{1} & \multirow[t]{6}{*}{$\begin{array}{l}\text { Wuhan, } \\
\text { China }\end{array}$} & $\begin{array}{l}\text { Case: } 34 \text { year old COVID-19 positive mother } \\
\text { at } 40 \text { weeks gestation. }\end{array}$ \\
\hline & & & & Delivery: Caesarean section. \\
\hline & & & & $\begin{array}{l}\text { Variables tested: Neonate's nasopharyngeal } \\
\text { swab, placenta, and umbilical cord blood. }\end{array}$ \\
\hline & & & & $\begin{array}{l}\text { Results: Neonate tested positive for SARS- } \\
\text { CoV-2 via RT-PCR at } 36 \text { hours after birth. } \\
\text { Placenta and cord blood negative for SARS- } \\
\text { CoV-2 via RT-PCR. }\end{array}$ \\
\hline & & & & Timing of placenta analysis: Unspecified. \\
\hline & & & & Vertical transmission: Inconclusive evidence. \\
\hline Li et al & June 2020 & 1 & Zhejiang, & Case: 30 year old COVID-19 positive mother \\
\hline
\end{tabular}


at 35 weeks gestation.

Delivery: Emergency caesarean section.

Variables tested: Neonate's nasopharyngeal swab, blood, urine, faeces; and amniotic fluid, umbilical cord blood, placenta, and mother's breast milk.

Results: All negative for SARS-CoV-2 via RTPCR.

Timing of placenta analysis: On delivery day.

Vertical transmission: Inconclusive evidence.

$\begin{array}{llll}\text { Penfield } & 8 \text { May } & 11 & \text { New York, } \\ \text { et al }{ }^{13} & 2020 & & \text { USA }\end{array}$

Case: 11 COVID-19 positive mothers ranging from 22 to 40 years old and 26 to 41 weeks gestation.

Delivery: 4 caesarean sections and 7 vaginal deliveries.

Variables tested: Neonate's nasopharyngeal swab, placenta, and membrane (between amnion and chorion),

Results: 3 placental samples tested positive for SARS-CoV-2 via RT-PCR. All 3 in women with severe to critical COVID-19 at time of caesarean section. First study to identify SARS-CoV-2 in placental samples. None of 11 infants tested positive for SARS-CoV-2 on day 1-5 of life or displayed symptoms.

Timing of placenta analysis: Within 30 minutes after delivery.

Vertical transmission: No clinical findings of vertical transmission but findings indicate possibility of intrapartum viral exposure as per study conclusion.

$\begin{array}{llll}\text { Patanè } & 18 \text { May } & 22 & \begin{array}{l}\text { Bergamo, } \\ \text { Italy }\end{array} \\ \text { et al }{ }^{14} & 2020 & & \text {. }\end{array}$

Case: 22 COVID-19 positive mothers.

Delivery: Caesarean sections and vaginal deliveries.

Variables tested: Neonate's nasopharyngeal swab and placenta.

\section{Results:}

Case 1: Vaginally delivered at 37 weeks gestation and tested positive from nasopharyngeal swab obtained immediately after birth, at 24 hours and 7 days. Neonate remained asymptomatic. Skin-to-skin contact was not permitted but breastfeeding was allowed. 
Case 2: Delivered via emergency caesarean section at 35 weeks gestation and tested positive from nasopharyngeal swab on day 7 with no contact between mother and neonate during this period. Test at birth was negative.

Timing of placenta analysis: At birth.

Vertical transmission: First study to identify SARS-CoV-2 in the mother, neonate and fetal side of placental tissues via RT-PCR.

Findings support possibility of vertical transmission in utero.

Hosier et 23 June al ${ }^{15} 2020$
1

Connecticut, USA
Case: 35 year old COVID-19 positive mother presented at 22 weeks gestation with severe preeclampsia.

Delivery: Termination of pregnancy via dilation and evacuation to reduce risk of maternal morbidity and death.

Variables tested: Umbilical cord blood, placenta, and fetal heart and lung tissues.

Results: Placenta and umbilical cord tested positive for SARS-CoV-2 via RT-PCR. Foetus tested negative. Findings suggest COVID-19 may have contributed to placental inflammation that resulted in early-onset preeclampsia and worsening maternal disease.

Timing of placenta analysis: Unspecified.

Vertical transmission: Inconclusive evidence.

$\begin{array}{llll}\begin{array}{l}\text { Ferraiolo } \\ \text { et al }\end{array}{ }^{16} & 22 \text { June } & 1 & \text { Genoa, Italy }\end{array}$

Case: 30 year old asymptomatic COVID-19 positive mother presented at 38 weeks gestation. Routine nasopharyngeal swabs confirmed infection in mother after delivery of neonate.

Delivery: Emergency caesarean section due to breech presentation.

Variables tested: Neonate's nasopharyngeal swab and placenta.

Results: Placenta positive for SARS-CoV-2 via RT-PCR. Neonate tested negative for SARSCoV-2 via RT-PCR.

Timing of placenta analysis: After delivery.

Vertical transmission: Study design is unsuitable to definitely support causal relationship between COVID-19 and placental infection and vertical transmission. 


$\begin{array}{llll}\text { Baud et } & 30 \text { April } & 1 & \begin{array}{l}\text { Lausanne, } \\ \text { Switzerland }\end{array} \\ \text { al }{ }^{17} & 2020 & & \begin{array}{l}\text { Sw } \\ \text { S }\end{array}\end{array}$

Case: 28 year old COVID-19 positive mother presented at 19 weeks gestation with a miscarriage.

Delivery: Vaginal delivery.

Variables tested: Placenta and fetal axillae, meconium, mouth, blood, lung, liver and thymus.

Results: Fetal swabs tested negative for SARS-CoV-2 via RT-PCR. Placenta tested positive for SARS-CoV-2.

Miscarriage may be related to placental infection with SARS-CoV-2.

Timing of placenta analysis: After delivery.

Vertical transmission: Inconclusive evidence. Lack of vertical transmission may be related to the stage of fetal development and short time of maternal infection.

$\begin{array}{llll}\text { Liu et } & 25 & 1 & \begin{array}{l}\text { Wuhan, } \\ \text { China }\end{array} \\ \text { al }^{18} & \text { February } & & \end{array}$

Chen et 1 March al $^{19} \quad 2020$
Case: 34 year old COVID-19 positive mother delivered newborn at 40 weeks.

Delivery: Caesarean section.

Variables tested: Neonate's nasopharyngeal swab, plasma serum and whole blood, placenta, vaginal mucus, mother's breast milk and umbilical cord blood.

Results: All negative for SARS-CoV-2 via RTPCR.

Timing of placenta analysis: Unspecified.

Vertical transmission: Inconclusive evidence.

Wuhan, Case: 3 COVID-19 positive mothers.

China
Delivery: Caesarean section.

Variables tested: Neonate's nasopharyngeal swab, placenta, fetal membranes and umbilical cord.

Results: All negative for SARS-CoV-2 via RTPCR.

Timing of placenta analysis: Unspecified.

Vertical transmission: Inconclusive evidence. 


\section{Discussion}

Baud et al and Hosier et al's studies describe two women suffering an adverse outcome during their pregnancy, notably miscarriage and severe preeclampsia respectively $[17,15]$. The miscarriage occurred in a symptomatic 28 year old woman at 19 weeks gestation. Baud et al concluded that the miscarriage appeared to be related to placental infection with SARS-CoV-2 which demonstrated mixed inflammatory infiltrates composed of neutrophils and monocytes on histological examination. Contamination during delivery was deemed unlikely given that all swabs from the foetus including the axillae, meconium, mouth and fetal blood were negative [17].

Wong et al reported a $57 \%$ miscarriage rate in a study of 12 pregnant women conducted during the 2002 SARS epidemic. They attributed this to acute or chronic placental insufficiency caused by severe maternal respiratory failure and hypoxemia thereby reducing uterine placental flow [20].

Hosier et al's study showed a 35 year old COVID-19 positive woman who presented at 22 weeks gestation with severe preeclampsia. This patient chose to terminate her pregnancy due to her heightened risk of maternal morbidity and mortality. High levels of SARS-CoV-2 were identified in the placenta and the invasion of intervillous macrophages was also seen on histology. Hosier et al concluded that COVID-19 may have contributed to placental inflammation resulting in early-onset preeclampsia and worsening maternal disease. It is important to note, however, that this patient was previously diagnosed with gestational hypertension which is a risk factor for her later developing preeclampsia in this pregnancy. No definitive evidence for fetal infection was described [15].

Shanes et al examined 16 placentas in COVID-19 positive women. The placentas showed features of maternal vascular malperfusion, most prominently decidual arteriopathy and increased incidence of chorangiosis. Although, placental swabs were not performed which makes it unclear whether it was a local phenomenon or a systemic phenomenon [5]. Similarly, Hosier et al showed similar risk factors for maternal vascular malperfusion, i.e. gestational hypertension and preeclampsia [15]. This may tentatively imply a link between COVID-19 and severe preeclampsia.

Mulvey et al analysed five COVID-19 positive mothers' placentas and concluded a thrombotic fetal vascular malformation phenomenon along with probable placental thrombosis lead to placental insufficiency. All five newborns were successfully delivered which may be attributed to the mothers developing COVID-19 closer to full term. Mulvey et al hypothesize that infection earlier in the gestational course may have more serious consequences such as placental insufficiency with associated miscarriages or low birth weight infants [22]. This may be why the two adverse outcomes in our study described by Hosier et al and Baud et al occurred during the second trimester.

Of the 11 studies we analysed for our literature review, Patanè et al's is the only study which supports the possibility of vertical transmission in utero on the basis of their finding of positive SARS-CoV-2 infection 
in the maternal, neonatal and placental tissue. One neonate tested positive at birth, 24 hours and on day 7 and the other only tested positive on day 7. Both of these women's placentas exhibited signs of chronic intervillositis accompanied by the presence of macrophages in the villous and intervillous space [14].

Dong et al showed elevated IgM antibody levels 2 hours after birth in a neonate born to a mother with COVID-19 suggesting that vertical transmission is possible, even if it is uncommon. This neonate also had elevated cytokines and a leucocytosis. IgM antibodies do not cross the placenta and normally appear 3 to 7 days after infection suggesting the infection occurred in utero. Confusingly, this infant repeatedly tested negative for SARS-CoV-2 on the nasopharyngeal swabs [23]. It is important to consider the accuracy of nasopharyngeal and oral swab RT-PCR assays for SARS-CoV-2 which is deemed to have a sensitivity of between $56 \%$ and $83 \%$ [24].

The major limitation of our study is the small sample size of only 45 COVID-19 positive pregnant women and thus we cannot conclusively rule out the possibility of vertical transmission, though we deem it unlikely. However, we can consider that COVID-19 may affect the placental tissue due to the detection of the virus in certain cases.

\section{Conclusion}

After reviewing multiple studies and investigating the nature of placental physiology in SARS-CoV-2 positive mothers we conclude that there is no concrete evidence of vertical transmission occurring between mother and infant.

However, due to the novelty of the pandemic this small number of studies represent low levels of evidence due to the inconsistencies across the different studies reported. As the cases continue to rise worldwide, we expect the evidence to become more concrete on this topic with the development of more robust case control studies and long-term follow-up with the mothers and children.

Our literature review highlights the urgent need for a large scale study to be designed investigating the effects of COVID-19 on pregnant women by using RT-PCR to test the mother, placenta, vaginal fluid, breast milk and infant for SARS-CoV-2 at various stages of transmission.

\section{References}

1. World Health Organization (2020) WHO Director-General's opening remarks at the media briefing on COVID-19. https://www.who.int/dg/speeches/detail/who-director-general-s-opening-remarks-at-themedia-briefing-on-covid-19-11-march-2020. Accessed: 1 July 2020

2. European Centre for Disease Prevention and Control (2020) COVID-19 situation update worldwide, as of 1 July 2020. https://www.ecdc.europa.eu/en/geographical-distribution-2019-ncov-cases. Accessed: 1 July 2020 
3. Dashraath P, Wong JLJ, Lim MXK et al. (2020) Coronavirus disease 2019 (COVID-19) pandemic and pregnancy. Am J Obstet Gynecol 222(6):521-531. doi:10.1016/j.ajog.2020.03.021

4. Lopes de Sousa ÁF, Carvalho HEF, Oliveira LB et al. (2020) Effects of COVID-19 Infection during Pregnancy and Neonatal Prognosis: What Is the Evidence?. Int J Environ Res Public Health. 17(11):4176. doi:10.3390/ijerph17114176

5. Shanes ED, Mithal LB, Otero S et al. (2020) Placental Pathology in COVID-19. Am J Clin Pathol. 154(1):23-32. doi:10.1093/ajcp/aqaa089

6. Lackey KA, Pace RM, Williams JE et al. (2020) SARS-CoV-2 and human milk: what is the evidence? [published online ahead of print, 2020 May 30]. Matern Child Nutr. 2020;e13032. doi: $10.1111 / \mathrm{mcn} .13032$

7. Juan J, Gil MM, Rong Z et al. (2020) Effect of coronavirus disease 2019 (COVID-19) on maternal, perinatal and neonatal outcome: systematic review. Ultrasound Obstet Gynecol. 56(1):15-27. doi:10.1002/uog.22088

8. Schwartz DA, Graham AL. (2020) Potential Maternal and Infant Outcomes from (Wuhan) Coronavirus 2019-nCoV Infecting Pregnant Women: Lessons from SARS, MERS, and Other Human Coronavirus Infections. Viruses. 12(2):194. doi:10.3390/v12020194

9. Wang X, Zhou Z, Zhang J et al. (2020) A case of 2019 Novel Coronavirus in a pregnant woman with preterm delivery [published online ahead of print, 2020 Feb 28]. Clin Infect Dis. 2020;ciaa200. doi:10.1093/cid/ciaa200

10. Fan C, Lei D, Fang C et al. (2020) Perinatal Transmission of COVID-19 Associated SARS-CoV-2: Should We Worry? [published online ahead of print, 2020 Mar 17]. Clin Infect Dis. 2020;ciaa226. doi:10.1093/cid/ciaa226

11. Yu N, Li W, Kang Q et al. (2020) Clinical features and obstetric and neonatal outcomes of pregnant patients with COVID-19 in Wuhan, China: a retrospective, single-centre, descriptive study. Lancet Infect Dis. 20(5):559-564. doi:10.1016/S1473-3099(20)30176-6

12. Li Y, Zhao R, Zheng S et al. (2020) Lack of Vertical Transmission of Severe Acute Respiratory Syndrome Coronavirus 2, China. Emerg Infect Dis. 26(6):1335-1336. doi:10.3201/eid2606.200287

13. Penfield CA, Brubaker SG, Limaye MA et al. (2020) Detection of SARS-CoV-2 in Placental and Fetal Membrane Samples [published online ahead of print, 2020 May 8]. Am J Obstet Gynecol MFM. 2020;100133. doi:10.1016/j.ajogmf.2020.100133

14. Patanè L, Morotti D, Giunta MR et al. (2020) Vertical transmission of COVID-19: SARS-CoV-2 RNA on the fetal side of the placenta in pregnancies with COVID-19 positive mothers and neonates at birth [published online ahead of print, 2020 May 18]. Am J Obstet Gynecol MFM. 2020;100145. doi:10.1016/j.ajogmf.2020.100145

15. Hosier H, Farhadian SF, Morotti RA et al. (2020) SARS-CoV-2 infection of the placenta [published online ahead of print, 2020 Jun 23]. J Clin Invest. 2020;139569. doi:10.1172/JCI139569

16. Ferraiolo A, Barra F, Kratochwila C et al. (2020) Report of Positive Placental Swabs for SARS-CoV-2 in an Asymptomatic Pregnant Woman with COVID-19. Medicina (Kaunas). 56(6):306. 
doi:10.3390/medicina56060306

17. Baud D, Greub G, Favre G et al. (2020) Second-Trimester Miscarriage in a Pregnant Woman With SARS-CoV-2 Infection [published online ahead of print, 2020 Apr 30]. JAMA. 323(21):2198-2200. doi:10.1001/jama.2020.7233

18. Liu W, Wang Q, Zhang Q et al. (2020) Coronavirus disease 2019 (COVID-19) during pregnancy: A case series. Preprints 2020;2020020373. https://www.preprints.org/manuscript/202002.0373/v1. Accessed 1 July 2020

19. Chen S, Huang B, Luo DJ et al. (2020) Pregnant women with new coronavirus infection: a clinical characteristics and placental pathological analysis of three cases. Chin J Pathol 49(5):418-423. doi:10.3760/cma.j.cn112151-20200225-00138

20. Wong SF, Chow KM, Leung TN et al. (2004) Pregnancy and perinatal outcomes of women with severe acute respiratory syndrome. Am J Obstet Gynecol. 191(1):292-297. doi:10.1016/j.ajog.2003.11.019

21. Mulvey JJ, Magro CM, Ma LX et al. (2020) Analysis of complement deposition and viral RNA in placentas of COVID-19 patients [published online ahead of print, 2020 Apr 25]. Ann Diagn Pathol. 46:151530. doi:10.1016/j.anndiagpath.2020.151530

22. Dong L, Tian J, He S et al. (2020) Possible Vertical Transmission of SARS-CoV-2 From an Infected Mother to Her Newborn [published online ahead of print, 2020 Mar 26]. JAMA. 323(18):1846-1848. doi:10.1001/jama.2020.4621

23. Kokkinakis I, Selby K, Favrat B et al. (2020 Covid-19 diagnosis :clinical recommendations and performance of nasopharyngeal swab-PCR. Rev Med Suisse. 16(689):699-701. 